\title{
LITERATURA POPULAR - POTENCIALIZANDO SABERES E MEMÓRIA COLETIVA
}

\author{
Maria de Lourdes Dionizio Santos, Universidade Federal de Campina Grande (UFCG) \\ lourdslourds@gmail.com
}

\begin{abstract}
RESUMO
Trata-se da realização de um Projeto de Extensão voltado à formação de professores da rede pública do sertão nordestino e discentes do Curso de Letras do Centro de Formação de Professores da Universidade Federal de Campina Grande (CFP/UFCG), executado no referido Centro, com vista a aprimorar o conhecimento do público beneficiado sobre Literatura Popular/Regional. Nessa perspectiva, abordamos a poética oral e escrita de autores nordestinos, no intuito de ampliar o conhecimento do público beneficiado. Partindo desses pressupostos, recorremos a autores que elucidam questões que perpassam temáticas suscitadas pelos textos lidos. Destarte, contribuímos com a formação docente, potencializando a recepção dessa estética e difundindo a Cultura Popular/Regional.
\end{abstract}

Palavras-chave: Literatura Popular. Memória Coletiva. Formação Continuada. Conhecimento Simbólico.

\section{INTRODUÇÃO}

Conceber o Nordeste como um celeiro artístico no cenário nacional, cujo (re)conhecimento ultrapassa suas fronteiras, é um fato incontestável, haja vista ser esta região um campo profícuo de criação e produção genuínas, não apenas no âmbito da arte popular, como também de outras formas de expressão artística, consolidando, assim, a cultura brasileira. Entretanto, algumas inquietações aparecem, quando, lecionando em um Curso de Letras de um Centro de Formação de Professores, situado no sertão nordestino, à Literatura Popular não é assegurado um lugar específico, no respectivo Curso. Somemos a isso a reivindicação de alunos do referido Curso, que questionam a não existência dessa disciplina em sua grade curricular. Pensemos também no desejo de se fazer uma Pós-Graduação nesse campo de estudo, sem, contudo, se ter uma base na educação formal, uma vez que, sendo e vivendo na região Nordeste, a formação artística e cultural, de algum modo, torna-se familiar. É justo nessa familiarização que muitas vezes flagramos o preconceito com a própria identidade cultural, que, muitas vezes, torna-se resistência ou negação da negação identitária. Herdeiros que somos da cultura do outro, pensemos, por exemplo, na língua que falamos, 
legado imposto pelos colonizadores, que tantas vezes precisamos discutir o que é "certo" ou "errado", e tem rendido teses e livros nas áreas da linguística. Ora, se a língua que falamos é "herdada", sentimo-nos, muitas vezes, inseguros em expressá-la. Mas, que dizer de outras formas de manifestação de nossa identidade, quando falamos de linguagem poética ou literária, ou de manifestações artísticas e culturais que, ao nascermos, nos encontramos imersos nesse berço que abriga a criação da gente humilde, que, em sua simplicidade, nos propicia tanto prazer com sua poesia, despreocupado com o "domínio" da língua considerada “culta"? Por que, então, a arte popular não tem recebido o devido respaldo em lugares que julgamos conhecê-la vastamente, embora não a valorize numa proporção que corresponda à sua contribuição para a formação e o desenvolvimento da sociedade? Por que motivo as pessoas não apreciam os bens e valores simbólicos de sua região? Essas inquietações nos moveram a elaborar este Projeto, no sentido de inferir sobre a realidade que nos envolve, com vistas a contribuir com o público-alvo a que este trabalho é destinado, propiciando-lhe respaldo intelectual e incentivo profissional, visto que se trata de professores de escolas públicas, ou futuros docentes a quem nos dirigimos em nossa tarefa cotidiana de educar.

Partindo desses pressupostos, realizamos o Projeto de Extensão intitulado: Literatura Popular: leituras e inferências sobre saberes, vivências e memória coletiva no sertão nordestino, no intuito de promover o estudo da literatura popular com base na leitura de textos poéticos do público-alvo, formado por alunos do Curso de Letras do Centro de Formação de Professores (CFP/UFCG), bem como de professores de escolas públicas de Cajazeiras e de cidades circunvizinhas, com vistas a ampliar, aprimorar e inferir sobre saberes, vivências e memória coletiva, compartilhando experiências e corroborando com a identidade cultural e a formação do referido público.

O propósito deste Projeto partiu da necessidade de se aprofundar e disseminar o conhecimento simbólico coletivo da Região Nordeste, a partir da leitura de textos da literatura popular, em prosa ou em verso, no sentido de promover e ampliar o conhecimento sobre os bens imateriais, bem como instigar o gosto do público-alvo pelo estudo da estética e da cultura regional, tendo em vista a importância de um olhar mais atento para a apreciação dos valores simbólicos que constituem esse conhecimento.

Refletindo sobre a razão que instiga os artistas, principalmente escritores e poetas, à produção de suas obras, constatamos que são vários os fatores que concorrem para a efetividade dessa produção. Dentre tais fatores, preponderam a genialidade dos criadores da arte popular regional, o legado artístico e cultural deixado no Nordeste, por ocasião da 
chegada dos portugueses ao Brasil, a semiaridez do solo e, ainda, o subjugo político, além de uma série de conflitos decorrentes das antinomias vivenciadas pelo povo dessa região. Tratase, aqui, de condições sociais, políticas, econômicas, históricas e geográficas da região, que, sendo precárias, paradoxalmente, instigam o artista a celebrar, através da arte, os acontecimentos da vida e os costumes desse povo, gerando uma riqueza cultural que se propaga, partindo do particular/regional para o nacional e o universal.

Não obstante as adversidades enfrentadas pelo povo nordestino, encontramos, em meio à natureza hostil, diversos artistas empenhados de forma resistente em seu ofício criador, contribuindo com vasta produção, resultante de sua observação, criatividade e conhecimento sobre o imaginário coletivo.

Nessa perspectiva, apreciamos o modo como os nossos poetas, escritores e artistas encontram ideias para a criação de suas obras, nas mais variadas formas de expressão de sua sensibilidade. Ou seja, é nas obras desses artistas, poetas e escritores que presenciamos a celebração da cultura popular - a experiência e a prática dos costumes da gente nordestina, a exemplo da oralidade, a qual se faz perceber no culto à tradição dos valores imateriais e simbólicos, repercutidos nos hábitos que se manifestam em cada atitude dessa gente.

Neste particular, nos deteremos na área da literatura popular, já conhecida no cenário nacional e internacional, sem, contudo, encontrar o merecido apreço na própria região de origem, a fim de trabalharmos a produção poética oral/popular de escritores e poetas nordestinos, no intuito de ampliar o conhecimento do público-alvo deste Projeto, propiciandolhe uma experiência de leitura, reflexão e discussão com base em textos dessa poética.

Neste Projeto, lançamos um olhar especial para a Literatura de Cordel, para promover o estudo dessa poesia, ao mesmo tempo em que rendemos tributo a esta importante estética que muito tem contribuído para o desenvolvimento da sociedade nordestina e brasileira.

Ao abordarmos o estudo sobre a literatura de cordel, ressaltamos que esse gênero era cantado em círculos de pessoas e recintos familiares, levando adiante a memória cultural, transmitida às gerações subsequentes da sociedade. Posteriormente, o cordel passou a ser escrito em forma de folhetos, vendido em feiras livres, obtendo também função informativa e de instrução para a população local, além de fruição e efetivo exercício e manutenção da memória coletiva.

As nossas origens histórico-culturais, que coincidem com as raízes da literatura de cordel, encontram-se na Espanha e na França. De Portugal foi importado o nome "cordel", derivativo de cordão, por ser comercializado em cordão, nas feiras livres do Nordeste, 
conforme afirmam os pesquisadores do assunto. Entretanto, há que se fazer referência, ainda que breve, ao que aconteceu historicamente na Europa, especialmente em Portugal, quando este se lançou pelo mar, empreendendo suas navegações.

Dessa forma, estaremos contribuindo com a disseminação dos saberes e vivências, bem como da memória coletiva, potencializando sua recepção, propiciando reconhecimento e maior visibilidade às diversas modalidades de arte regional nordestina. Além disso, estaremos suprindo uma carência urgente no Curso de Letras do CFP, assim como dos professores da rede pública de ensino de Cajazeiras e cidades adjacentes.

\section{Abordagem teórica}

Tomamos como aporte teórico para fundamentar este Projeto o pensamento de autores de obras da Literatura Popular, bem como de críticos versados nessa literatura, cujas obras abordem discussão acerca de questões que perpassem a realidade representada nas obras literárias, de forma que contribuam para elucidar debates que surjam no decurso da realização deste Projeto.

Neste sentido, fazemos recurso ao que afirma Luís da Câmara Cascudo ${ }^{1}$, em sua obra Literatura oral no Brasil, a respeito dos folhetos, que, "Embora assinados, esses folhetos revelam apenas a utilização de temas remotos, correntes no Folclore ou na literatura apologética de outrora, trazidos nos contos morais, filhos dos 'exemplos"”.

Cascudo $^{2}$ assinala que "essa matéria pertence à Literatura Oral. Foi feita para o canto, para a declamação, para a leitura em voz alta. Serão depressa absorvidos nas águas da improvisação popular, assimilados na poética dos desafios, dos versos [...] nos sertões do Brasil".

Cascudo $^{3}$ também atribui à Literatura Oral "Todos os autos populares, danças dramáticas, as jornadas dos pastoris, as louvações das lapinhas, Cheganças, Bumba-meu-boi, Fandango, Congos, o mundo sonoro e policolor dos reisados, aglutinando saldos de outras representações apagadas na memória coletiva”.

À maneira desses "elementos vivos da Literatura Oral", embora a literatura de cordel tenha perdido força em determinados períodos de sua existência, ela vem, de forma

\footnotetext{
${ }^{1}$ CASCUDO, Luís da Câmara. Literatura oral no Brasil. 2. ed. são Paulo: Global, 2006. p. 22.

${ }^{2}$ Id., Ibidem, p. 22.

${ }^{3}$ Id., Ibidem, p, 22.

${ }^{4}$ Id., Ibidem, p, 22.
} 
persistente, resistindo contra a avalanche de informações e produtos lançados pela indústria da cultura, no mercado.

Nesse sentido, ao fazermos uma breve retrospectiva sobre a poesia popular do Nordeste, encontramos, no Estado da Paraíba, uma expressiva representação de poetas desse gênero, conforme atestam estudos que tratam dessa literatura, a exemplo da pesquisa de José Ribamar Lopes, ${ }^{5}$ que apresenta a seguinte síntese: “1830 é considerado, historicamente, o ponto de partida da poesia popular nordestina. Em torno dessa data nasceram Ugulino de Sabugi - o primeiro cantador que se conhece, e - e seu irmão Nicandro, ambos filhos de Agostinho Nunes da Costa, o pai da poesia popular" (LOPES, 1982, p. 17).

Lopes (1982, p. 18) ressalta que "até 1920, a poesia popular escrita e oral, ganhou fôlego e outros poetas apareceram nos estados do Nordeste". Esse mesmo pesquisador assinala que, "Só nesse período foram registrados 2.500 poetas populares".

Dentre os poetas cordelistas, Leandro Gomes de Barros destaca-se como um dos melhores de sua época. Ele iniciou "O movimento editorial do cordel", ao lado de "Chagas Batista e Pirauá”. Em 1902, publicou um folheto em Campina Grande. [...] Há um outro de Leandro, publicado no Recife, em 1904". 7

Conforme Lopes ${ }^{8}$ relata, por volta de 1945, ocorreu um fenômeno desencadeado pelos fatores social, econômico e cultural, que ficou conhecido por "germe destruidor no comércio de folhetos". A partir de então, segundo o mesmo pesquisador,

Uma fase de decadência em conseqüência de novos fatores determinantes das transformações sociais, como o rádio, o cinema, a aceleração do processo de industrialização do País, a construção de Brasília, a facilidade de novos meios de transporte, estimulando as migrações internas no Brasil. Esses fatores alteram a mentalidade do homem rural nordestino, o grande consumidor da poesia popular escrita e oral. ${ }^{9}$

Essas considerações de Lopes conferem à literatura de cordel um lugar de destaque, pela sua relevância na configuração da cultura nordestina, conforme acrescenta, em seguida, o referido pesquisador:

\footnotetext{
${ }^{5}$ LOPES, José Ribamar (Org.). Literatura de cordel: antologia. 3. ed. Fortaleza: Banco do Nordeste do Brasil, 1994. (Coleção Monografia, 14), p. 18.

${ }^{6}$ Id., Ibidem, p. 18.

${ }^{7}$ Id., Ibidem, p. 18-19.

${ }^{8}$ Id., Ibidem, p. 19.

${ }^{9}$ Id., Ibidem, p. 19.
}

Revista de Pesquisa Interdisciplinar, Cajazeiras, n. 2, suplementar, p. 284-293, set. de 2017. 
Uma fase de decadência em conseqüência de novos fatores determinantes das transformações sociais, como o rádio, o cinema, a aceleração do processo de industrialização do País, a construção de Brasília, a facilidade de novos meios de transporte, estimulando as migrações internas no Brasil. Esses fatores alteram a mentalidade do homem rural nordestino, o grande consumidor da poesia popular escrita e oral. ${ }^{10}$

Essas considerações feitas por Lopes conferem à literatura de cordel um lugar de destaque, pela relevância de seu papel na disseminação da cultura nordestina, bem como "Pela sua vitalidade, constância e abrangência temática, a literatura de cordel se apresenta como fenômeno dos mais singulares e relevantes da cultura do povo nordestino". ${ }^{11}$

Nessa esteira de raciocínio, ao tratar sobre a editoração dos folhetos de cordel no Nordeste, Rosilene Alves de Melo ${ }^{12}$ cita o trabalho de Gilmar de Carvalho, pesquisador que se debruçou "sobre a literatura de cordel produzida em Juazeiro do Norte", Ceará, e "deu visibilidade ao aspecto editorial do cordel, relegado até então ao esquecimento". Em sua obra Arcanos e verso: trajetórias da literatura de cordel, a referida pesquisadora discorre de modo fluente e profundo sobre "a produção do patrimônio cultural da Tipografia São Francisco" fazendo "registros transmitidos através da oralidade e da escrita". Rosilene Melo ${ }^{13}$ acrescenta que, "Atualmente, o conjunto de folhetos editado pela Tipografia São Francisco encontra-se à disposição dos pesquisadores em diversas instituições no Brasil”.

Em seu relevante trabalho, Rosilene Melo ${ }^{14}$ afirma que "Os folhetos constituem uma fonte histórica privilegiada, pois reúnem as linguagens oral, escrita e iconográfica"; a referida pesquisadora busca transcender a "hermenêutica dos textos" e "problematizar as condições particulares de sua produção, os saberes e práticas que transitam em torno dessa literatura, bem como as estratégias forjadas para a circulação dessa arte entre um número cada vez maior de pessoas".

Vale citar, também, a pesquisa de Ana Maria de Oliveira Galvão, intitulada "Processos de inserção de analfabetos e semi-analfabetizados no mundo da cultura escrita (1930-1950)", na qual a autora ressalta que a escola não é "a única via de mediação entre a leitura e a escrita", uma vez que outras "práticas educativas têm ocorrido, ao longo do tempo, fora da

\footnotetext{
${ }^{10}$ Id., Ibidem, p. 19.

${ }^{11}$ Id., Ibidem, p. 19.

${ }^{12}$ MELO, Rosilene Alves de. Arcanos e verso: trajetórias da literatura de cordel. Rio de Janeiro: 7Letras, 2010. p. 24.

${ }^{13}$ Id., Ibidem, p. 24.

${ }^{14}$ Id., Ibidem, p. 24.
}

Revista de Pesquisa Interdisciplinar, Cajazeiras, n. 2, suplementar, p. 284-293, set. de 2017. 
escola e, às vezes, com maior força do que se considera, principalmente para determinados grupos sociais, em determinada época". 15

Galvão afirma que "ao estudar a literatura de cordel”, desenvolvendo sua pesquisa, verificou "que, para alguns segmentos sociais, esse tipo de literatura, tradicionalmente classificada como popular, representava um dos únicos contatos que tinham com a escrita, a leitura e o impresso". ${ }^{16}$ A partir dessa constatação, a pesquisadora buscou "(re)construir no público leitor, as maneiras de ler, os papéis atribuídos à leitura e as formas de apropriação da leitura de folhetos de cordel, no período de 1930 a 1950, em Pernambuco". ${ }^{17}$ Os leitores/ouvintes entrevistados pela pesquisadora declararam que

os folhetos constituíram o objeto de leitura e/ou audição mais presente. Para os analfabetos, leitura em voz alta sempre mediada por alguém alfabetizado: em geral os filhos ou vizinhos e, eventualmente, o cônjuge. Os outros, [...] liam os cordéis em voz alta para um grupo e, em outros momentos, realizavam uma leitura solitária, silenciosa. ${ }^{18}$

Ao fazer uma abordagem sobre o "Desafio e repentismo do caipira de São Paulo", J. M. Luyten, ${ }^{19}$ no subtítulo "Correspondentes nordestinos", tece o seguinte comentário:

Não há dúvida alguma de que as modalidades poéticas populares do Nordeste são muito mais conhecidas nacional e internacionalmente do que as versões paulistas. [...] Devido à migração de nordestinos para outras regiões do Brasil, notadamente São Paulo, verificamos, hoje em dia, que a capital paulista se tornou um dos maiores centros produtores e emissores de poesia popular nordestina. [...] A cultura popular nordestina [...] expandiu-se, sobretudo no século XX, de tal modo que hoje é possível notar sua influência em todos os meios culturais do País, desde a literatura das classes dominantes ao teatro e cinema.

Luyten $^{20}$ atribui a essa "hegemonia nordestina", "o surgimento, no fim do século passado, da poesia popular escrita, hoje chamada de literatura de cordel. Embora a base seja

\footnotetext{
${ }^{15}$ GALVÃO, Ana Maria de Oliveira. Processos de inserção de analfabetos e semi-analfabetizados no mundo da cultura escrita (1930-1950). Revista brasileira de educação, Campinas, SP, n. 16, p. 81-94, jan/fev/mar/abr. 2001, p. 81.

${ }^{16}$ Id., Ibidem, p. 81.

${ }^{17}$ GALVÃO, Ana Maria de Oliveira apud GALVÃO, Ana Maria de Oliveira. Op. Cit., p. 81-82.

${ }^{18}$ GALVÃO, Ana Maria de Oliveira. Op. Cit., p. 82.

${ }^{19}$ LUYTEN, Joseph M. Desafio e repentismo do caipira de São Paulo. In: BOSI, Alfredo. (Org.). Cultura brasileira: temas e situações. p.79.

${ }^{20}$ Id., Ibidem, p. 79.
}

Revista de Pesquisa Interdisciplinar, Cajazeiras, n. 2, suplementar, p. 284-293, set. de 2017. 
essencialmente o aspecto oral, há numerosas obras impressas". Dentre "as mais de 20 000," “cerca de 10000 já foram catalogadas por Átila de Almeida". Essa quantidade suntuosa de impressão vem seguida de várias edições dos folhetos.

De acordo com Luyten ${ }^{21}$, "Não há literatura popular no mundo que possua números tão impressionantes de divulgação e penetração. [...] $O$ fato de a poesia do Nordeste ser parcialmente impressa faz com que ela seja muito mais perene e influente".

As análises dos pesquisadores supramencionados nos levam a refletir sobre a importância da leitura de cordel para a vida de muitos brasileiros. Quem de nós não teve a oportunidade de ouvir e/ou ler um folheto de cordel? Quem não de nós não se deleitou com esse tipo de literatura, lendo ou ouvindo as peripécias dos heróis ou anti-heróis desses folhetos? Por que negligenciamos a nossa cultura, no âmbito da prática docente, ou no cotidiano? O que leva o povo a negar sua identidade, e desprestigiar sua arte? A partir dessas questões, discutiremos sobre a importância e o significado da literatura de cordel, tendo em vista a contribuição dada à sociedade por essa forma de expressão e de conhecimento, embora quase sempre, desvalorizada.

\section{METODOLOGIA}

Como procedimentos metodológicos, realizamos este Projeto instrumentalizados na leitura de textos de autores da Literatura Popular oral e/ou escrita, em prosa e/ou em verso, estabelecendo discussões a respeito das temáticas abordadas nos referidos textos, inferindo sobre questões que perpassam a realidade e instigando o público-alvo a tomar parte nessas tarefas, compartilhando sua experiência. Desse modo, no decurso da execução das atividades realizamos oficinas e estudos em grupo, através de leitura de textos da Literatura Popular, assim como de obras teóricas e críticas voltadas para essa área de conhecimento, quando corroboraram para o aprimoramento da formação do público-alvo.

Tomamos como referência para a execução do Projeto, estudo de textos de época e gênero diversos da Literatura Popular do Nordeste, dentre os quais destacamos: poesia oral, conto, crônica, teatro e romanceiro. Dentre os autores e obras referenciados para estudo, elencando um expressivo número deles. Além destas, outras obras e autores surgiram, durante o desenvolvimento do Projeto.

\footnotetext{
${ }^{21}$ Id., Ibidem, p. 80.
} 
Assim, a prática de leitura e discussão em sala de aula esteve pautada em textos previamente selecionados segundo sua compatibilidade e pertinência do conteúdo em relação à proposta do Projeto, atendendo às necessidades do referido público.

A seleção de textos para estudo e os trabalhados durante os encontros com o público coube à equipe executora do Projeto.

Dessa forma, as discussões sobre as leituras dos textos propiciaram a interação do público-alvo, o qual pode se expressar, manifestando sua opinião a respeito das questões sugeridas pelas leituras realizadas.

Além da seleção de textos elaborada pela equipe, também as pessoas envolvidas fizeram uma leitura prévia dos textos selecionados para estudo, no sentido de melhor compreender a discussão e poder inferir sobre o conteúdo abordado.

Assim sendo, a prática do projeto ocorreu em sala de aula ou outros recintos disponíveis do CFP/UFCG (Centro de Formação de Professores da Universidade Federal de Campina Grande), com o público-alvo formado, prioritariamente, pelos professores da rede pública de ensino do Município de Cajazeiras e adjacências, bem como pelos alunos regularmente matriculados no Curso de Graduação em Letras (UAL/CFP/UFCG), em Cajazeiras, Paraíba.

Os encontros para a realização das atividades deste projeto aconteceram uma vez por semana, precedido de reuniões preparatórias entre a Equipe executora do Projeto.

Eventualmente, quando se fez necessário, utilizamos Auditórios do CFP, para a execução das tarefas do Projeto.

\section{CONCLUSÃO}

As diferenças que se observam entre a cultura do povo e a da elite que, ao nosso entender, acontecem, também, entre a literatura popular e a erudita, constituem um vício que se repete de longas datas. Isso se constata ao fazermos um breve retorno às nossas origens histórico-culturais.

Desse modo, buscamos realizar este Projeto, discutindo questões suscitadas no decurso de sua execução, promovendo debate acerca da contribuição da arte e da cultura, encontradas na vasta produção dos artistas nordestinos, junto ao público-alvo acima mencionado.

\section{REFERÊNCIAS BIBLIOGRÁFICAS}


BOSI, Alfredo. (Org.). Cultura brasileira: temas e situações. 4. ed. São Paulo: Ática, 2006. (Série Fundamentos, 18)

CASCUDO, Luís da Câmara. Literatura oral no Brasil. 2. ed. são Paulo: Global, 2006.

Civilização e cultura: pesquisas e notas de etnografia geral. Rio de Janeiro: José Olímpio; Brasília: INL, 1973. v. 2

CEARÁ. SECRETARIA DE CULTURA E DESPORTO. Antologia da literatura de cordel. Fortaleza, 1980. v. I e II.

DIEGUÉS JÚNIOR, Manuel et al. Literatura popular em verso: estudos. Belo Horizonte: Itatiaia; São Paulo: Editora da Universidade de São Paulo; Rio de Janeiro: Fundação Casa de Rui de Rui Barbosa, 1986.

GALVÃO, Ana Maria de Oliveira. Processos de inserção de analfabetos e semianalfabetizados no mundo da cultura escrita (1930-1950). Revista brasileira de educação, Campinas, SP, n. 16, p. 81-94, jan/fev/mar/abr. 2001.

LOPES, José Ribamar (Org.). Literatura de cordel: antologia. 3. ed. Fortaleza: Banco do Nordeste do Brasil, 1994. (Coleção Monografia, 14).

LUYTEN, Joseph M. Desafio e repentismo do caipira de São Paulo. In: BOSI, Alfredo. (Org.). Cultura brasileira: temas e situações. 4. ed. São Paulo: Ática, 2006. (Série Fundamentos, 18). p. 75-102.

Passos, 98).

O que é literatura popular. 5. ed. São Paulo: Brasiliense, 1992. (Coleção Primeiros

MELO, Rosilene Alves de. Arcanos e verso: trajetórias da literatura de cordel. Rio de Janeiro: 7Letras, 2010.

MINISTÉRIO DA EDUCAÇÃO E CULTURA. Literatura popular em verso. Rio de Janeiro: Fundação Casa de Rui Barbosa; Campina Grande, PB: Fundação Universidade Regional do Nordeste, 1976. Antologia. Tomo II. (Coleção de Texto da Língua Portuguesa Moderna; 4).

MONTELLO, Josué. Biblioteca educação é cultura. Rio de Janeiro: Bloch: FENAME, 1980. 